Original scientific paper

\title{
ELECTRIC VEHICLE CHARGING STATION LAYOUT BASED ON PARTICLE SWARM SIMULATION
}

\author{
Liu, J.-Y.; Liu, S.-F. \& Gong, D.-Q." \\ School of Economics \& Management, Beijing Jiaotong University, Beijing, China \\ E-Mail: dqgong@bjtu.edu.cn ( ${ }^{\#}$ Corresponding author)
}

\begin{abstract}
The construction layout of charging piles restricts the rapidly development of EVs. To address this area, this paper first simulates the current layout of charging piles in Beijing and finds that there is an unbalanced distribution problem of oversupply and idle resources. Then, based on the current situation, this study takes the total charge station construction cost as the objective function and unfolds in three levels, using MIP for conditional constraints. Finally, an improved particle swarm algorithm is employed to simulate electric vehicles by generating demand points in the region to obtain the optimum location of charging stations. This method overcomes the limitation of using static data in traditional research, and the simulation can reflect the dynamic law of electric vehicle operation, which is more consistent with the real situation. The calculation results show that the method adopted in this study can reasonably plan the layout of charging stations, relieve the charging pressure of some charging stations, and minimize the overall service cost of new charging stations based on the continuation of the existing layout.

(Received in July 2021, accepted in October 2021. This paper was with the authors 3 weeks for 1 revision.)
\end{abstract}

Key Words: Electric Car, Charging Station Layout, Simulation, PSO

\section{INTRODUCTION}

Transportation industry is an important branch of national economic development. Recently, with the progress of urban construction and high speed of economic operation, China's car ownership has been increasing, which also drives the development of economy to a certain extent. However, with the development of automobile industry, it also faces the problems of environmental pollution and energy shortage. The urgent demand for petroleum resources by traditional cars has a serious negative impact on the environment, which is contrary to the economic concept of green travel and sustainable development. The emergence of electric vehicles has brought a new breakthrough to solve these two problems. It can get rid of the dependence on petroleum resources and reduce air and noise pollution [1]. Therefore, promoting the transition from traditional gasoline vehicles to electric vehicles has become an important task for the automotive industry.

At present, with the vigorous implementation of new energy vehicles in China, the backwardness of electric vehicle charging infrastructure has been a key element restricting the development of electric vehicles. As the fundamental charging facility construction of electric vehicles in China has just started, the demand and actual distribution of electric vehicles have not yet been unified, and the layout planning of charging facilities has not formed a scientific theoretical system. Therefore, in the actual construction process, some charging facilities are idle and cannot be fully utilized; some charging facilities are in short supply and resources are tight. Therefore, it is very necessary to form a set of scientific, reasonable and practical planning and construction system of charging facilities network to realize the rational use of resources, meet the growing charging demand and promote the expansion of electric vehicle industry. 


\section{LITERATURE REVIEW}

In this paper, the following three aspects of EV charging station research are reviewed: (1) Electric vehicle charging demand prediction; (2) The location of charging facilities based on mathematical models; (3) The location of charging facilities based on big data simulation and statistical research.

\subsection{Electric vehicle charging demand prediction}

In the study of optimizing the layout of charging facilities, the first step is to estimate the charging requirements. In the absence of actual EV travel data, previous studies usually use static statistics as the basis for calculating charging demand. For instance, Kou et al. [2] used the size of population to approximate the electric vehicle charging requirements. Luo et al. [3] used a gray prediction model to build an EV ownership prediction model based on the national civil vehicle ownership statistics. Gompertz model was used by Ma et al. [4] to forecast the number of provincial car ownership between 2018 and 2050 in China. SadeghiBarzani et al. [5] used vehicle ownership as a proxy for estimating charging demand. Zhang et al. [6] used a cluster prediction method based on the clustering of charging curves to improve the precision of EV charging demand prediction. Although it is relatively easy to obtain static statistics, measurements based on static data such as GDP, number of inhabitants, car ownership, etc. cannot accurately reflect the dynamic changes in the number of EVs and charging demand. In recent years, more and more studies have been carried out to provide an analysis of the charging demand for electric vehicles based on actual traffic data. For example, Xing et al. [7] proposed a data-driven charging needs prediction model for electric vehicles, using the real trajectory data of Didi to predict the changes in electric vehicle charging demand on different dates and functional areas.

\subsection{The location of charging facilities based on mathematical models}

Currently, the research of EV charging station siting based on operations research is very common. The commonly used models include the following.

In terms of charging facility siting studies, the flow refuelling location model is widely used. Kuby et al. integrated the mileage parameters and established a flow refuelling location model $[8,9]$. In this model, the authors used the mileage limit as the basic constraint of the model and considered the backflow case. However, the model does not consider the upper limit of the energy supply capacity of the charging station. Therefore, the optimal solution may not be solved. Upchurch and Kuby took limited energy constraints as a consideration, which enabled the model to perform well in large-scale site selection, and named it the limited flow refuelling location model [10]. However, this model ignores the differences in customer needs and violates the laws of reality to a certain extent. In addition to the above methods, queuing theory, as a mathematical method used in the working process of random service systems, has also been applied many times in the location of charging facilities. Zhu et al. [11] used a queueing theory approach to calculate the charging stations capacity considering the non-random and random arrival of electric vehicles at charging stations. They proposed a charging station planning model and divided the service area of charging stations using Voronoi diagram. Previous studies in the field of electric vehicles have used queuing theory to simulate the time of arrival and departure of electric vehicles to estimate the capacity of V2G. However, most of them did not take into account the limitations of the queuing system. Varshosaz et al. [12] considered balancing, rescheduling, and re-examination in a finite source queuing network and proposed a queuing model-based service scheduling method before the charging station day. 
In additional to the above methods, other modelling approaches have been widely used in the siting of charging facilities. Hosseini and Sarder combined qualitative and quantitative analysis to develop a BN model considering subjective and objective factors to plan the layout and location of stations [13]. Hua and Xu developed a mobile EV maximum coverage model with minimum budget cost as an objective function to identify the number and the layout of both the charging stations and EVs [14].

Liu et al. [15] mainly analysed related factors such as geographic environment, and then screened and optimised the charging station sites, and built a model for the most optimal position and capacity on this basis. Chen et al. studied the process of electric taxi power changes over time [16], taking customer travel distance as the objective function, and then constructing a scientific and effective mathematical model of charging location. Yang et al. conducted an in-depth analysis of passenger charging characteristics and habits, and mainly used nested and polynomial driving to construct a mathematical model [17]. Hu et al. [18] presented a newly integrated MCDM method to determine the most appropriate site from multiple interrelated standards. Among them, the gray DEMATEL approach is applied to determine the weights of the criteria, and the UL-MULTIMOORA method is used to assess and to pick the best sites.

\subsection{The location of charging facilities based on big data simulation and statistical research}

Recently, big data and simulation technology are gradually being adopted to the layout of EV charging stations planning. Awasthi et al. [19] combined genetic algorithm with an improved traditional PSO, and used a hybrid algorithm to optimise the charging station in the Allahabad power distribution system. Similarly, Li and Wen [20] studied the dynamic job shop scheduling problem under random dynamic event disturbances and solved it using PSO. Baouche et al. introduced a way of allocating charging stations in the actual network. According to the travel OD matrix information, the energy demand is calculated and input as a parameter to an integer linear optimization procedure to decide the layout of stations [21]. Hui et al. [22] built a simulation model to optimize charging station planning with the aim of cost and customer loss minimization by considering the stochastic nature of charging demand and customer satisfaction factors, and used a two-stage simulation optimization algorithm for solution. González et al. analysed the temporal and spatial distribution of charging demand, established a simulation model, and decided the placement of EV stations on the basis of statistical analysis [23]. Chen et al. collected tens of thousands of residential travel and parking information, used regression analysis to predict demand, and established a mixedinteger programming model to plan the layout of stations [24]. Li et al. [25] also used the PSO to optimize the layout of EV charging stations to identify the number and location, which proved to be superior to the traditional k-means algorithm. Suryani et al. [26] created a simulation model for urban transportation planning based on system dynamics, performed a case study and drew conclusions.

\section{MODEL ESTABLISHMENT}

This chapter mainly establishes the location optimization model and constraint conditions of EV charging stations. The model's objective function in this thesis is set to minimise the total cost. According to the attributes and operation analysis of EV charging stations, the overall cost of station construction can be categorized into three categories: construction cost, operation cost and time cost. The operation cost can be classified into personnel cost, daily maintenance cost and administration cost; the time cost can be classified into the timeconsuming cost on the charging journey and the time cost of waiting in line (see Fig. 1). 


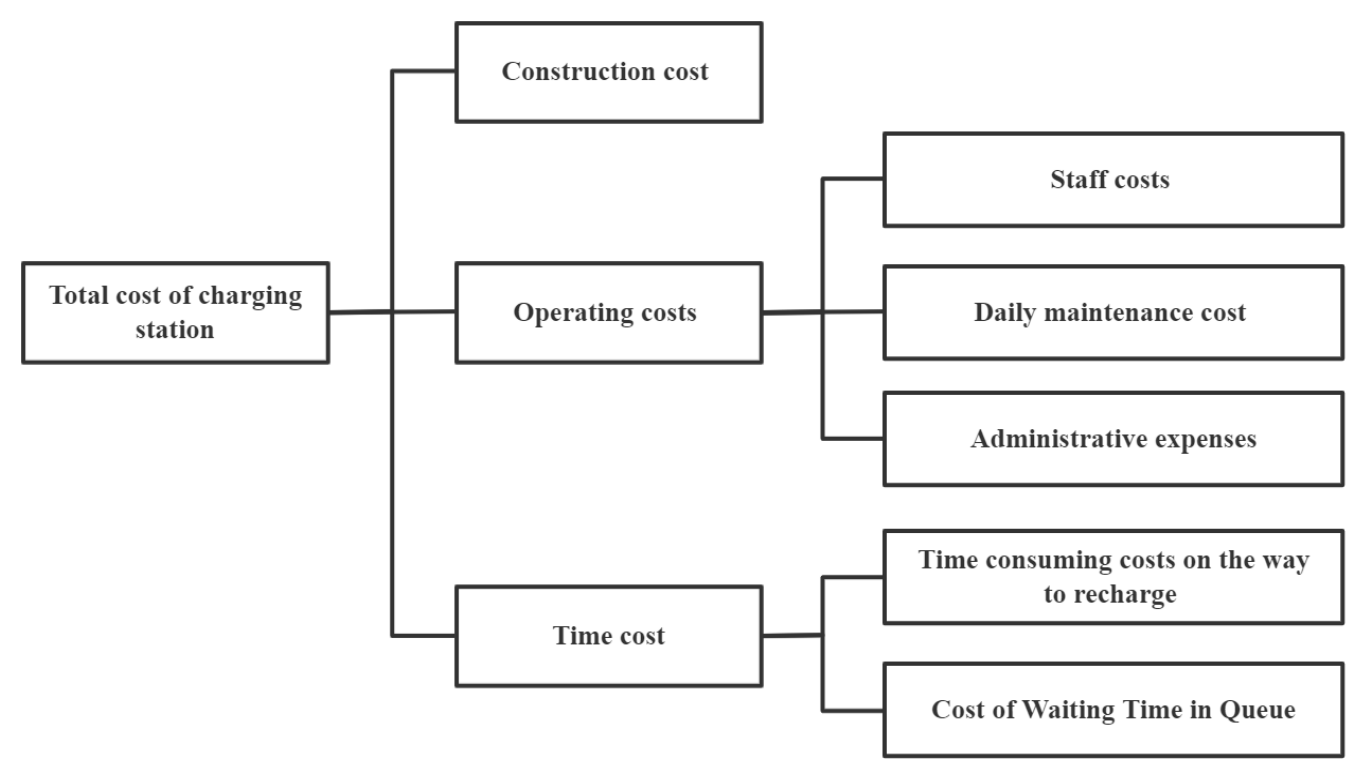

Figure 1: Total cost of charging station.

(1) Construction and operation costs

Construction cost can define as the construction cost of EV charging stations, including infrastructure procurement, site selection, equipment procurement costs, utilities, regulatory system, etc. In addition to fixed costs, construction costs are mainly related to the quantity of facilities in the station. The more charging facilities there are, the higher the construction cost. Operation cost refers to the expenses of the toll station in the actual operation process, including personnel cost, daily maintenance cost, daily income and expenditure management cost, etc.

(2) Time cost

The time-consuming cost of the charging process is the time it takes the customer to get from the demand location to the charging point. Typically, it is proportional to the length of the journey between the demand site and the service site. The further the distance, the higher the cost. Therefore, a reasonable EV charging station can effectively reduce the cost of customer's time on the road and improve customer convenience. The annual cost of queuing is the cost of queuing when the customer arrives at the demand site. In the actual charging queuing process, each charging station can be considered as a complete queuing system, which satisfies the M/M/S model. The customer arrival time obeys a Poisson distribution, while the toll process obeys a negative exponential distribution.

Before analysing the model, we first set some assumptions of the problem to make the model feasible and feasible solutions. 1. The annual construction and operating cost of all charging stations are determined and known; 2 . The upper limit of the service capacity of the station is known; 3 . There are limited number of charging station service centres.

Table I gives the meanings and symbols of the parameters in the layout evaluation problem.

The target function for this issue is the total cost of building an EV charging station:

$$
\begin{gathered}
\operatorname{MinZ}_{\text {cost }}=F_{c 1}+Z_{j} F_{c 2}+Z_{j} F_{c 3} \\
F_{c 1}=H_{0}+\sum_{j \in J}\left(T_{j c}\left(M_{j}\right) \frac{r_{0}\left(1+r_{0}\right)^{n}}{\left(1+r_{0}\right)^{n}-1}+T_{j s}\left(M_{j}\right)\right) \\
F_{c 2}=365 \sum_{i \in I} \sum_{j \in J} \delta \cdot S_{i j} \cdot m \cdot E_{e} \cdot P_{e} \\
F_{c 3}=365 \beta \sum_{j \in J}\left(W_{q}^{j} \sum_{i \in I} P_{e} \cdot m\right)
\end{gathered}
$$


Table I: Parameters setting.

\begin{tabular}{|c|c|c|}
\hline $\begin{array}{c}\text { Serial } \\
\text { number }\end{array}$ & $\begin{array}{c}\text { Variable } \\
\text { name }\end{array}$ & Variable description \\
\hline 1 & $Z_{\text {cost }}$ & The total cost of building an EV charging station \\
\hline 2 & $F_{c 1}$ & Construction and operating costs of EV charging stations \\
\hline 3 & $F_{c 2}$ & $\begin{array}{l}\text { Electricity and time-consuming costs of electric vehicles on their way to } \\
\text { charging stations }\end{array}$ \\
\hline 4 & $F_{c 3}$ & Cost of waiting in line at EV charging stations \\
\hline 5 & $T_{j c}\left(M_{j}\right)$ & $\begin{array}{l}\text { The annual construction cost function of charging station } j \text {. Related to the } \\
\text { number of charging facilities in the station }\end{array}$ \\
\hline 6 & $T_{j s}\left(M_{j}\right)$ & $\begin{array}{l}\text { The annual operating cost function of charging station } j \text {. Including personnel } \\
\text { costs, maintenance costs, management costs }\end{array}$ \\
\hline 7 & $H_{0}$ & Fixed investment costs of infrastructure such as land fees \\
\hline 8 & $r_{0}$ & Discount rate \\
\hline 9 & $n$ & Depreciation period \\
\hline 10 & $\delta$ & $\begin{array}{l}\text { Conversion factor of tortuous path between straight line distance and actual } \\
\text { distance }\end{array}$ \\
\hline 11 & $S_{i j}$ & The straight-line distance from EV $i$ to charging station $j$ \\
\hline 12 & $\mathrm{~m}$ & The number of electric vehicles that need to be charged daily \\
\hline 13 & $E_{e}$ & Average power consumption per kilometre \\
\hline 14 & $P_{e}$ & Charging price \\
\hline 15 & $\beta$ & Travel time cost \\
\hline 16 & $w_{q}^{j}$ & Expectation of waiting time in line at charging station $j$ \\
\hline 17 & $\mathrm{P}$ & Charger service intensity \\
\hline 18 & $P_{z}$ & Probability that all chargers are idle \\
\hline 19 & $\delta_{j}$ & Electric vehicle arrival rate \\
\hline 20 & $u_{i}$ & The abscissa of the location of the electric car \\
\hline 21 & $v_{i}$ & The ordinate of the location of the electric car \\
\hline 22 & $x_{j}$ & The abscissa of the location of the EV charging station \\
\hline 23 & $y_{j}$ & The ordinate of the location of the EV charging station \\
\hline 24 & $E_{\text {total }}$ & Total charging demand in the planned area \\
\hline 25 & $E_{\text {jmax }}$ & Maximum capacity of charging station \\
\hline 26 & $E_{\text {jmin }}$ & Minimum capacity of charging station \\
\hline 27 & $r_{i j}$ & The distance from the user to the charging point \\
\hline 28 & $r_{j}$ & Charging station service radius \\
\hline 29 & $d$ & The distance between two charging stations \\
\hline 30 & $N_{j}^{E V}$ & Number of electric vehicles within the service range of charging station $j$ \\
\hline 31 & $N_{j}$ & Number of charging devices in charging station $j$ \\
\hline 32 & $\alpha$ & Maximum simultaneous charging rate of electric vehicles \\
\hline
\end{tabular}

Each electric vehicle charging station can be described as a queuing system, and can be attributed to the M/M/S model. The expectation and cost of waiting time for electric vehicles are:

$$
\begin{gathered}
W_{q}=\frac{M_{j} P^{M_{j}+1} P_{z}}{\delta_{j} M_{j} !\left(M_{j}-P\right)^{2}} \\
P_{z}=\sum_{i=0}^{M_{j}-1} \frac{P^{i}}{i !}+\frac{M_{j} P^{M_{j}}}{M_{j}\left(M_{j}-P\right)}
\end{gathered}
$$


Among them, $Z_{i j}$ can only take 0 or 1 . When its value is 1 , it means that the user at demand point $j$ will choose to charge at candidate location $i$; when its value is 0 , the opposite is true.

Specifically, the constraints of the model are as follows:

Constraint (7) indicates that the charging capacity in the area served by charging station should be greater than the maximum charging demand:

$$
N_{j}^{E V} \cdot \alpha \leq N_{j}
$$

Constraint (8) means that the maximum radius of service of the charging points is supposed to be greater than the farthest user distance within the range:

$$
r_{i j} \leq r_{j}
$$

Constraint (9) means that the distance of any two adjacent charging points cannot be set too far and should be reasonable. So as to ensure that electric vehicles can drive normally and be charged in time.

$$
d \leq 2 r_{j}
$$

Constraint (10) indicates the number of charging stations:

$$
F\left(\frac{E_{\text {total }}}{E_{\text {jmax }}}\right) \leq N_{j} \leq F\left(\frac{c}{E_{\text {jmin }}}\right)
$$

For this scenario, constraints (11) to (14) are the regional constraints for the location of charging stations and demand points:

$$
\begin{aligned}
& x_{\min } \leq x_{j} \leq x_{\max } \\
& y_{\min } \leq y_{j} \leq y_{\max } \\
& x_{\min } \leq u_{i} \leq x_{\max } \\
& y_{\min } \leq v_{i} \leq y_{\max }
\end{aligned}
$$

0,1 decision variables are:

$$
z_{i j} \in(0,1)
$$

Because the building cost and operating cost are relatively fixed. Therefore, the following solution process will focus on $F_{c 2}$. Taking into account the nature of the study question, we will attempt to use simulation methods to analyse and solve the model. Therefore, in the next chapter, we use MATLAB to simulate the actual user demand points and the calculated corresponding charging station location, solve it with the particle swarm algorithm, and analyse and optimise the layout of the existing charging piles.

\section{SIMULATION CASE AND ANALYSIS}

\subsection{Simulation case}

For this research, 43 charging stations ("red dots") located in the centre of Beijing were selected for layout evaluation. As the traffic in Beijing is concentrated in the Fourth Ring Road, the distribution of electric vehicles is relatively dense in this area, and the construction of charging stations is relatively mature. Therefore, we select the data of the centre of Beijing (near and within the Fourth Ring Road) for research (Fig. 2). The data sources of the study are Baidu maps and http://www.evpartner.com/auto/pilemap.html. Figure below shows a partial screenshot of the distribution of electric vehicles in Beijing on the website [27].

Through simulation, we randomly generate 500 demand points on the map as the initial position of the EV, and the electric vehicle can drive arbitrarily within the specified range. 
Once the remaining battery kilometres are less than $10 \%$ of the maximum cruising range, the nearest charging station is selected for charging.

Through simulation, we can see charging stations have the problem of too low or too high charging frequency, indicating that the layout is unreasonable. We also found that the construction level of charging stations is more complete in the northern half of Beijing. Because the population in the north of Beijing is relatively concentrated, the city planning is relatively complete, and the transportation network is relatively mature. In contrast, the construction of charging stations in the southern half of Beijing is not mature enough and is still under construction. Therefore, for the southern half of the district, the planning and layout is particularly important. In recent years, the Beijing Municipal Government has also stepped up efforts to build the southern half of Beijing, like Fengtai District and other cities to promote the balanced development of the city's north and south. Based on the above reasons, we have planned the location of EV charging stations in the southern half of Beijing.

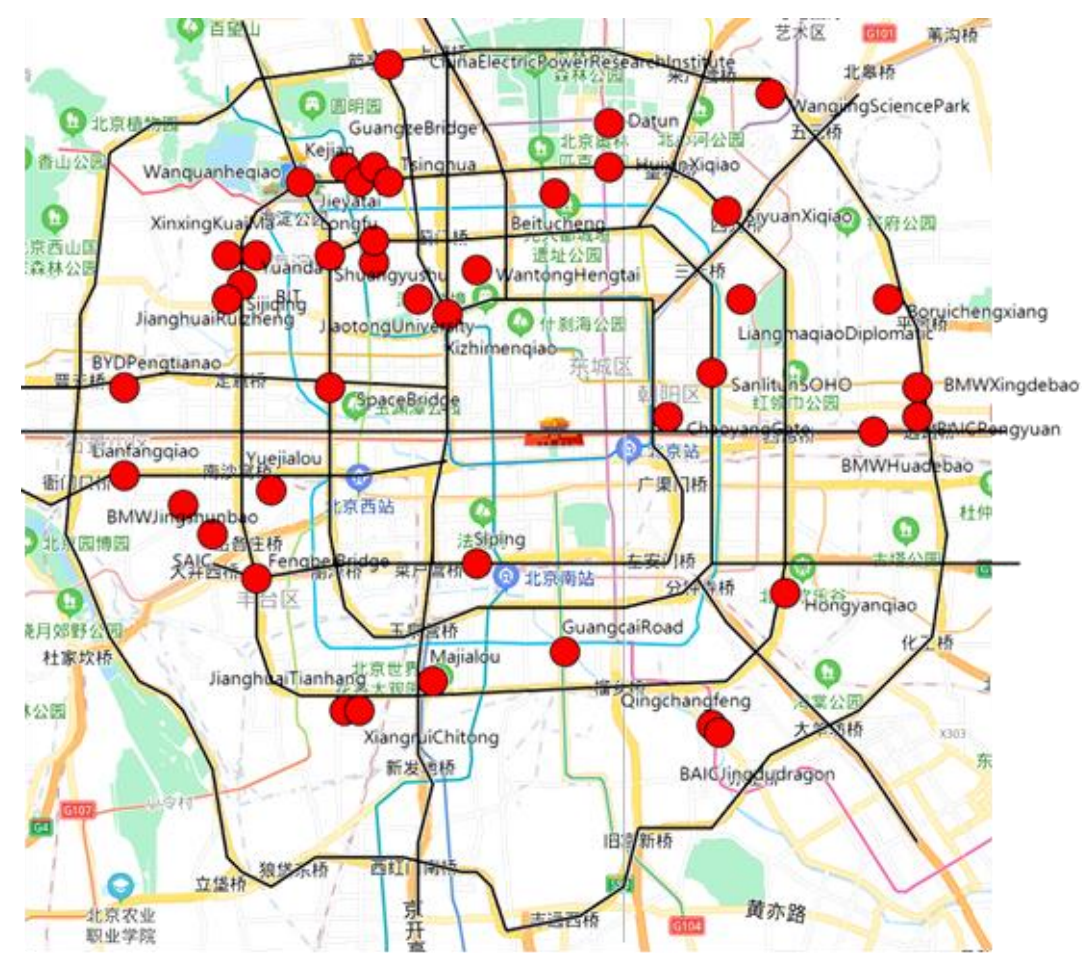

Figure 2: The distribution of electric vehicles in Beijing.

\subsection{Simulation results}

Eberhart and Kennedy firstly introduced Particle Swarm Optimization (PSO) in 1995, and the fundamental concept originated from the study of foraging behaviour of bird flocks. Particle Swarm Optimization (PSO) has been widely used in various industries because it involves few parameters and is easy to compute. PSO is also used in this study for problem solving.

(1) Program initialization. Set the appropriate parameters according to the actual situation. The initialization of the program includes setting the population size, the number of evolutionary generations, and the population size. Also, initialize the global historical optimal solution and store the updated particle positions for each generation.

(2) Particle update. As the number of iterations changes, the particle velocity, position coordinates, and adaptive particle variation are continuously updated.

(3) Distance and shortest distance. Calculate the distance from the EV demand point to the charging station service point to minimize the service cost of the trip. 
According to the planning situation of the North District, we will plan the location of 10 new charging stations in the South District. As shown in the figure, we randomly generate 100 points in the research area to simulate the demand points of electric vehicles.

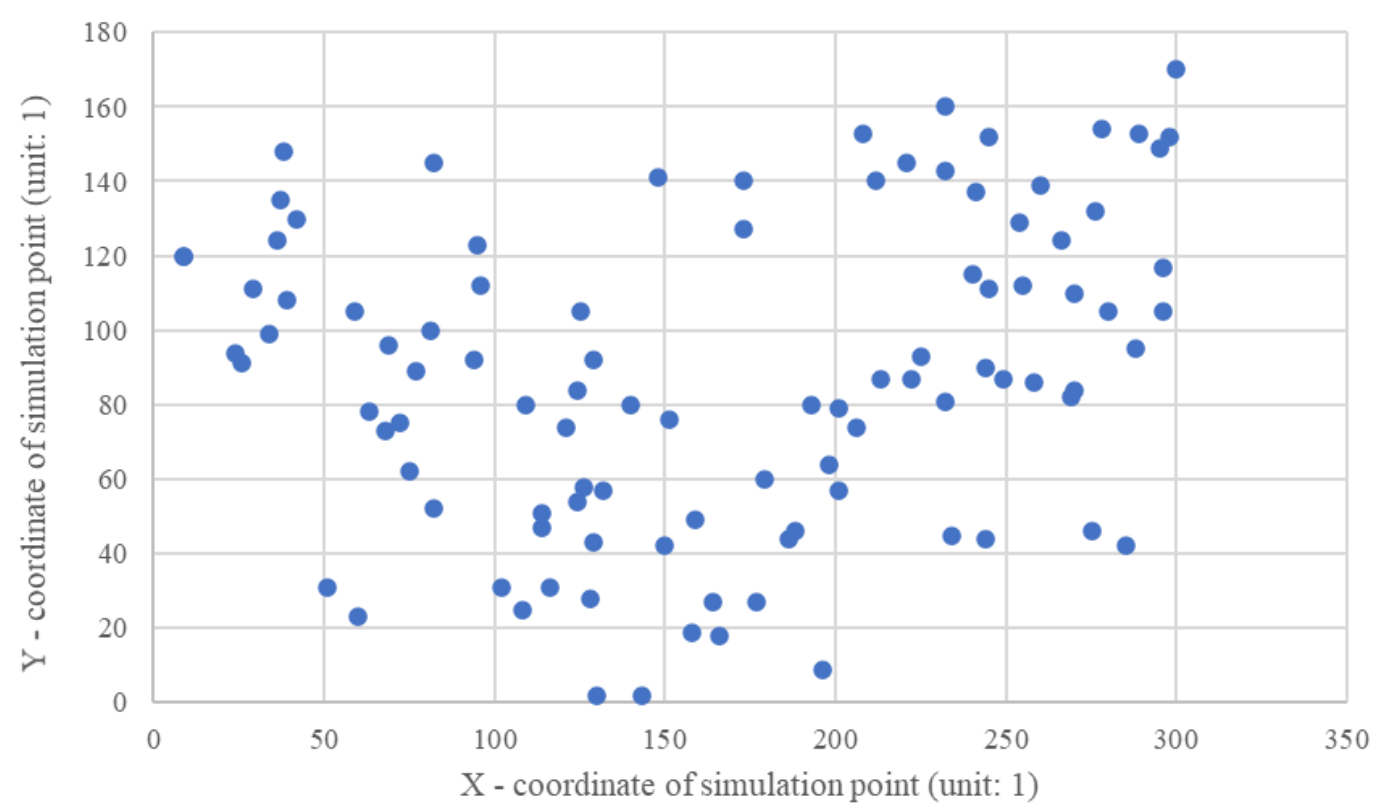

Figure 3: Distribution of simulated electric vehicles.

We use MATLAB to solve. The MATLAB software parameters are set as: particle population size popsize $=500$, evolution algebra gen $=100$, charging station location is set to 2 dimensions (depending on the dimension of the solution space in the fitness function), and the learning factor $c_{1}=c_{2}=2$. Calculated according to particle swarm algorithm. The demand point and the optimal site selection are shown in the Fig. 4. Furthermore, according to the iterative diagram, the selected position is more reasonable.
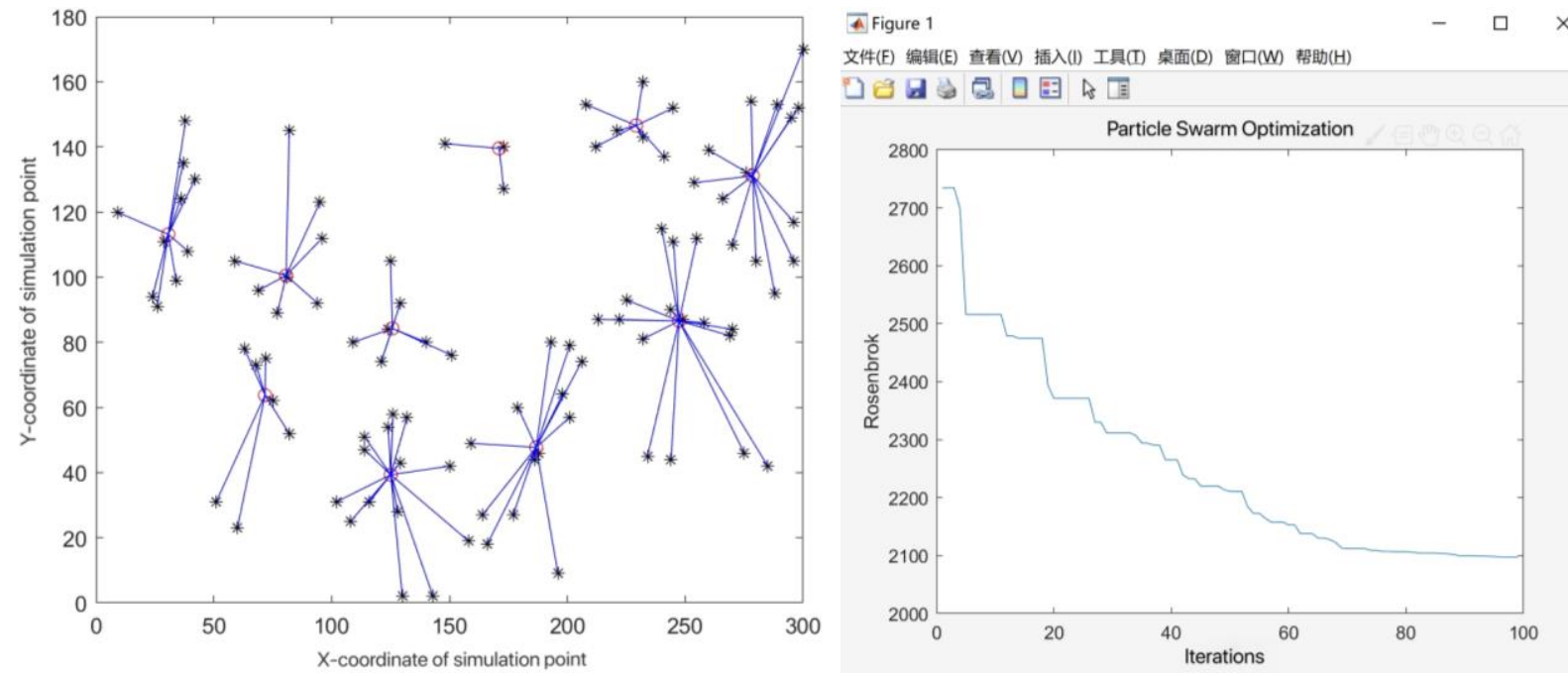

Figure 4: Particle swarm algorithm results.

Substitute the coordinates of each demand point into Eq. (3), and use the mathematical model of location selection as the fitness function of the particle swarm algorithm. Using MATLAB software to solve the particle swarm algorithm, the optimised charging station location coordinates are shown in Table II. 
Table II: Charging station location coordinates.

\begin{tabular}{|c|c|c|c|c|}
\hline $\begin{array}{c}\text { Demand } \\
\text { point }\end{array}$ & $\begin{array}{c}\text { Horizontal } \\
\text { coordinates }\end{array}$ & $\begin{array}{c}\text { Vertical } \\
\text { coordinates }\end{array}$ & $\begin{array}{c}\text { Number of } \\
\text { response points }\end{array}$ & $\begin{array}{c}\text { Access } \\
\text { ratio }\end{array}$ \\
\hline 1 & 30.67 & 113.1 & 10 & 10 \\
\hline 2 & 80.66 & 100.5 & 8 & 8 \\
\hline 3 & 71.7 & 63.75 & 7 & 7 \\
\hline 4 & 125.8 & 84.26 & 7 & 7 \\
\hline 5 & 125.1 & 39.32 & 14 & 14 \\
\hline 6 & 171.1 & 139.6 & 3 & 3 \\
\hline 7 & 186.8 & 47.74 & 13 & 13 \\
\hline 8 & 247.4 & 86.57 & 7 & 7 \\
\hline 9 & 278.7 & 131.1 & 16 & 16 \\
\hline 10 & 229.2 & 146.6 & 14 & 14 \\
\hline
\end{tabular}

\subsection{Result analysis}

According to the above calculation results. As shown in the figure, the red is the current layout, and the yellow point is the site selection of the new site. One of the sites is too close to the Majialou charging station, so we chose to discard this site and keep the original site.

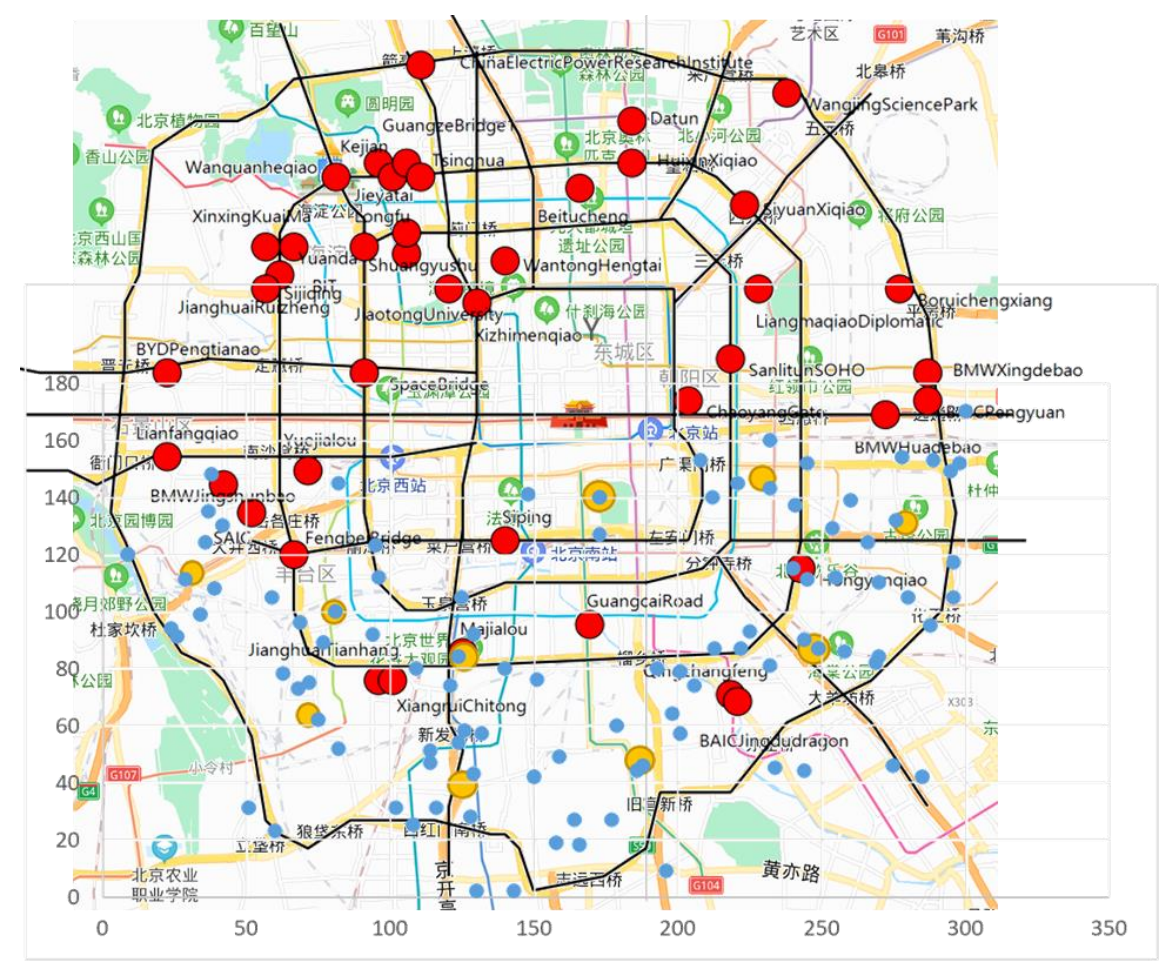

Figure 5: Layout planning of new and old charging stations.

We perform another simulation in the above-mentioned way, randomly generating 500 points as the initial location of the electric vehicle, and after the simulation results, we can get the following frequency distribution map of each charging station. Among them, the original charging stations with high frequency of visits and relatively tight charging pressure, after the construction of new charging stations, the current layout is more reasonable. It can be seen that the charging pressure of No. 13, 34, 10, 22, 27, and 28 charging stations has been effectively relieved, and the visit frequency is more balanced. At the meantime, the visit 
frequency of the nine newly constructed charging stations has been maintained to a relatively balanced and moderate state, indicating that the newly selected stations can play a more stable role. After the new site is built, charging resources are more evenly distributed. At the same time, the improved location service cost is lower and the response speed is faster. As shown in the figures below.
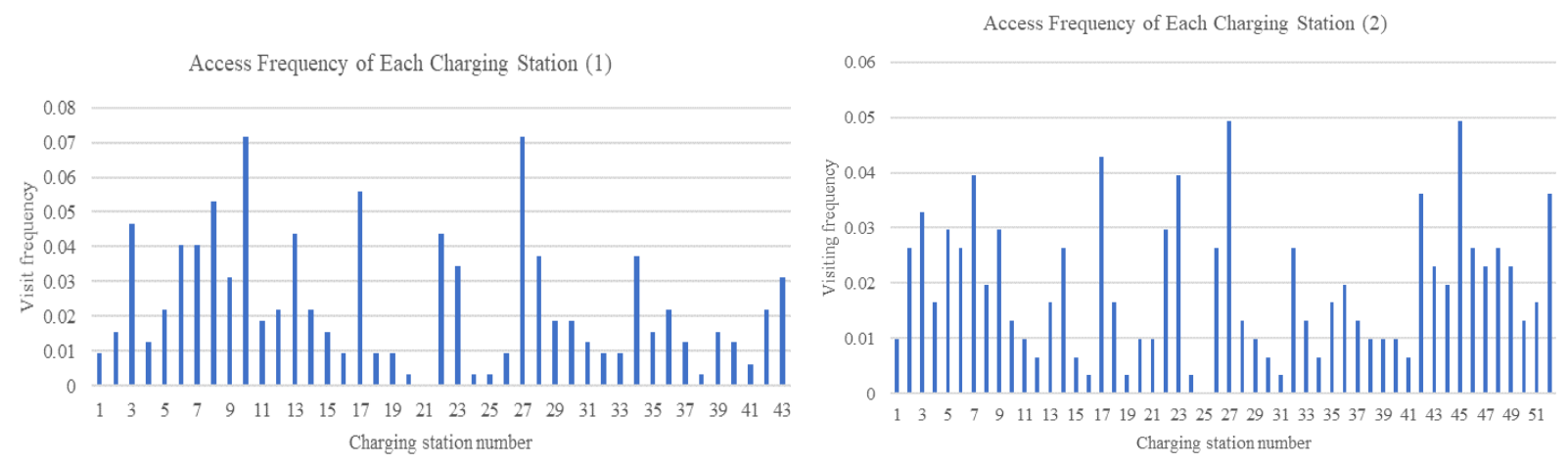

Figure 6: The charging frequency of each charging station before and after the layout site selection.

\section{CONCLUSION}

The placement of EV charging stations is extremely critical. A reasonable location can maximize the charging efficiency and minimize the cost to ensure the economic operation of the EVe industry. This paper takes the siting of the electric vehicle charging stations as the research direction, and provides a reasonable planning and arrangement for the construction of charging stations. Through a scientific theoretical model, the optimal position of charging stations is guided. The research results of this paper can be categorized into the following points:

(1) The layout of EV charging stations is obtained by means of simulation. Previous research mainly used static data such as the number of residents, the number of EVs, and GDP to estimate the demand for EVs, and to perform modelling solutions. Using these static data, it is often impossible to obtain the dynamic law of electric vehicles, and cannot reflect the real situation in reality. Therefore, this article uses particle swarm simulation to simulate electric vehicles in cities. It is more dynamic and in line with reality.

(2) Establish a MIP-based model of EV charging station location. The model takes cost as the target function, and aims to make the charging station construction cost, operation cost, time-consuming cost in charging process and queuing time cost minimized. Under the condition that the constraint conditions are met, the most optimal location is obtained. Using this objective function for modelling, you can invest the minimum cost, so as to obtain the maximum social effect.

(3) Modify the simulation parameters to adapt to the actual location layout. The paper simulates the relationship between the electric vehicle charging point and the vehicle to be served by randomly generating demand points, and uses MATLAB to perform PSO to solve the layout planning of the charging station. One of the advantages of this method is that it can modify the location distribution of demand points, the number of cars and other parameters according to the actual situation, so that the model is suitable for many situations. It has the characteristics of flexibility and versatility.

(4) Taking Beijing as the research object, a case calculation of charging station location is carried out. The planned location of new EV charging stations minimizes the cost. And under the new electric vehicle layout plan, the layout is more balanced and reasonable, and the uneven distribution of the original charging station resources is alleviated. It has practical significance, and at the same time verifies the validity of the model. 


\section{ACKNOWLEDGEMENTS}

This work was supported by MOE (Ministry of Education in China) Project of Humanities and Social Sciences under Grant 19YJC630043, Beijing Social Science Foundation under Grant 19JDGLA002, 18JDGLA018, and was partially supported by Beijing Logistics Informatics Research Base. We appreciate their support very much.

\section{REFERENCES}

[1] Guo, J. (2020). Research on distribution network planning considering electric vehicle charging station, Electrical Engineering, Vol. 8, No. 1, 8-17, doi:10.12677/JEE.2020.81002

[2] Kou, L.; Liu, Z. F.; Zhou, H. (2010). Modeling algorithm of charging station planning for regional electric vehicle, Modern Electric Power, Vol. 27, No. 4, 48-52

[3] Luo, H.; Ruan, J.; Li, F. (2011). Study on the electric vehicles ownership and planning for the construction of charging infrastructure, 2011 Asia-Pacific Power and Energy Engineering Conference, 4 pages, doi:10.1109/APPEEC.2011.5748974

[4] Ma, L.; Wu, M.; Tian, X.; Zheng, G.; Du, Q.; Wu, T. (2019). China's provincial vehicle ownership forecast and analysis of the causes influencing the trend, Sustainability, Vol. 11, No. 14, Paper 3928, 26 pages, doi:10.3390/su11143928

[5] Sadeghi-Barzani, P.; Rajabi-Ghahnavieh, A.; Kazemi-Karegar, H. (2014). Optimal fast charging station placing and sizing, Applied Energy, Vol. 125, 289-299, doi:10.1016/ j.apenergy.2014.03.077

[6] Zhang, L.; Sun, Z.; Wang, W. X.; Li, X.; Zhou, Y.; Huang, Q.; Chen, Y. (2018). Electric vehicle charging facility planning method based on curves clustering forecast, Modern Electric Power, Vol. 35, No. 4, 21-26, doi:10.19725/j.cnki.1007-2322.2018.04.004

[7] Xing, Q.; Chen, Z.; Zhang, Z.; Huang, X.; Leng, Z.; Sun, K.; Wang, H. (2019). Charging demand forecasting model for electric vehicles based on online ride-hailing trip data, IEEE Access, Vol. 7, 137390-137409, doi:10.1109/ACCESS.2019.2940597

[8] Capar, I.; Kuby, M.; Leon, V. J.; Tsai, Y.-J. (2013). An arc cover-path-cover formulation and strategic analysis of alternative-fuel station locations, European Journal of Operational Research, Vol. 227, No. 1, 142-151, doi:10.1016/j.ejor.2012.11.033

[9] Kuby, M.; Lines, L.; Schultz, R.; Xie, Z.; Kim, J.-G.; Lim, S. (2009). Optimization of hydrogen stations in Florida using the Flow-Refueling Location Model, International Journal of Hydrogen Energy, Vol. 34, No. 15, 6045-6064, doi:10.1016/j.ijhydene.2009.05.050

[10] Upchurch, C.; Kuby, M. (2010). Comparing the $p$-median and flow-refueling models for locating alternative-fuel stations, Journal of Transport Geography, Vol. 18, No. 6, 750-758, doi:10.1016/ j.jtrangeo.2010.06.015

[11] Zhu, J.; Li, Y.; Yang, J.; Li, X.; Zeng, S.; Chen, Y. (2017). Planning of electric vehicle charging station based on queuing theory, The Journal of Engineering, Vol. 2017, No. 13, 1867-1871, doi:10.1049/joe.2017.0655

[12] Varshosaz, F.; Moazzami, M.; Fani, B.; Siano, P. (2019). Day-ahead capacity estimation and power management of a charging station based on queuing theory, IEEE Transactions on Industrial Informatics, Vol. 15, No. 10, 5561-5574, doi:10.1109/TII.2019.2906650

[13] Hosseini, S.; Sarder, M. D. (2019). Development of a Bayesian network model for optimal site selection of electric vehicle charging station, International Journal of Electrical Power \& Energy Systems, Vol. 105, 110-122, doi:10.1016/j.ijepes.2018.08.011

[14] Hua, G.; Xu, Y. (2019). Optimal deployment of charging stations and movable charging vehicles for electric vehicles, Journal of System and Management Sciences, Vol. 9, No. 1, 105-116, doi:10.33168/JSMS.2019.0106

[15] Liu, Z. P.; Wen, F. S.; Ledwich, G. (2013). Optimal planning of electric-vehicle charging stations in distribution systems, IEEE Trans on Power Delivery, Vol. 28, No. 1, 102-110, doi:10.1109/TPWRD.2012.2223489

[16] Chen, L.; Zhang, W.; Huang, Y.; Zhang, D. (2014). Research on the charging station service radius of electric taxis, 2014 IEEE Conference and Expo Transportation Electrification AsiaPacific, 4 pages, doi:10.1109/ITEC-AP.2014.6941081 
[17] Yang, Y.; Yao, E.; Yang, Z.; Zhang, R. (2016). Modeling the charging and route choice behavior of BEV drivers, Transportation Research Part C: Emerging Technologies, Vol. 65, 190-204, doi:10.1016/j.trc.2015.09.008

[18] Hu, C.; Liu, M.; Zhou, M.; Tian, G. (2019). An integrated multi-criteria decision making approach to location planning of electric vehicle charging stations, IEEE Transactions on Intelligent Transportation Systems, Vol. 20, No. 1, 362-373, doi:10.1109/TITS.2018.2815680

[19] Awasthi, A.; Venkitusamy, K.; Padmanaban, S.; Selvamuthukumaran, R.; Blaabjerg, F.; Singh, A. K. (2017). Optimal planning of electric vehicle charging station at the distribution system using hybrid optimization algorithm, Energy, Vol. 133, 70-78, doi:10.1016/j.energy.2017.05.094

[20] Li, J. X.; Wen, X. N. (2020). Construction and simulation of multi-objective rescheduling model based on PSO, International Journal of Simulation Modelling, Vol. 19, No. 2, 323-333, doi:10.2507/IJSIMM19-2-CO8

[21] Baouche, F.; Billot, R.; Trigui, R.; el Faouzi, N.-E. (2014). Efficient allocation of electric vehicles charging stations: optimization model and application to a dense urban network, IEEE Intelligent Transportation Systems Magazine, Vol. 6, No. 3, 33-43, doi:10.1109/ MITS.2014.2324023

[22] Hui, L.; Chao, Y.; Shaozheng, Y.; Xuepu, J. (2017). Research on electric vehicle siting of charging stations and configuration of charging pile based on simulation optimization method, Computer Simulation, Vol. 34, No. 8, 168-172

[23] González, J.; Alvaro, R.; Gamallo, C.; Fuentes, M.; Fraile-Ardanuy, J.; Knapen, L.; Janssens, D. (2014). Determining electric vehicle charging point locations considering drivers' daily activities, Procedia Computer Science, Vol. 32, 647-654, doi:10.1016/j.procs.2014.05.472

[24] Chen, T. D.; Kockelman, K. M.; Khan, M. (2013). Locating electric vehicle charging stations: parking-based assignment method for Seattle, Washington, Transportation Research Record, Vol. 2385, No. 1, 28-36, doi:10.3141/2385-04

[25] Li, W.; Yang, L.; Wen, Z.; Chen, J.; Wu, X. (2021). On the optimization strategy of EV charging station localization and charging piles density, Wireless Communications and Mobile Computing, Vol. 2021, Paper 6675841, 13 pages, doi:10.1155/2021/6675841

[26] Suryani, E.; Hendrawan, R. A.; Adipraja, P. F. E.; Indraswari, R. (2020). System dynamics simulation model for urban transportation planning: a case study, International Journal of Simulation Modeling, Vol. 19, No. 1, 5-16, doi:10.2507/IJSIMM19-1-493

[27] Tang, M.; Gong, D.; Liu, S.; Lu, X. (2017). Finding key factors affecting the locations of electric vehicle charging stations: a simulation and ANOVA approach, International Journal of Simulation Modelling, Vol. 16, No. 3, 541-554, doi:10.2507/IJSIMM16(3)CO15 